This item was submitted to Loughborough's Research Repository by the author.

Items in Figshare are protected by copyright, with all rights reserved, unless otherwise indicated.

\title{
Does sand content in spawning substrate result in early larval emergence? Evidence from a lithophilic cyprinid fish
}

PLEASE CITE THE PUBLISHED VERSION

https://doi.org/10.1111/eff.12435

\section{PUBLISHER}

(c) Wiley

\section{VERSION}

AM (Accepted Manuscript)

\section{PUBLISHER STATEMENT}

This is the peer reviewed version of the following article: BASIC, T. ... et al, 2018. Does sand content in spawning substrate result in early larval emergence? Evidence from a lithophilic cyprinid fish. Ecology of Freshwater Fish, 28 (1), pp.110-122, which has been published in final form at https://doi.org/10.1111/eff.12435. This article may be used for non-commercial purposes in accordance with Wiley Terms and Conditions for Use of Self-Archived Versions.

\section{LICENCE}

CC BY-NC-ND 4.0

\section{REPOSITORY RECORD}

Basic, Tea, J. Robert Britton, Stephen P. Rice, and Andrew G. Pledger. 2019. "Does Sand Content in Spawning Substrate Result in Early Larval Emergence? Evidence from a Lithophilic Cyprinid Fish". figshare. https://hdl.handle.net/2134/34800. 
1 Does sand content in spawning substrate result in early larval emergence? Evidence from

2 a lithophilic cyprinid fish.

3

4 Tea Bašić ${ }^{1,4}$

5 J. Robert Britton ${ }^{1}$

$6 \quad$ Stephen Rice ${ }^{2}$

7 Andrew Pledger ${ }^{2,3}$

8

$9 \quad{ }^{1}$ Department of Life and Environmental Sciences, Faculty of Science and Technology,

10 Bournemouth University, Poole, Dorset, BH12 5BB, UK (TBasic@bournemouth.ac.uk;

11 rbritton@bournemouth.ac.uk)

$12{ }^{2}$ Geography Department, Loughborough University, Epinal Way, Loughborough,

13 Leicestershire, LE11 3TU, UK (S.Rice@lboro.ac.uk; A.G.Pledger@lboro.ac.uk).

$14 \quad{ }^{3}$ AP Environmental Solutions, 15 Hillside, Sawston, Cambridge, UK, CB22 3BL (andrew@ ap15 environmental.com)

16

17 Running title: Barbus barbus larval emergence

18 Keywords: Fine sediment, Sand content; Non-salmonid lithophils, Barbus barbus; Egg to 19 emergence survival; Larval emergence.

20 Corresponding author: Tea Bašić; +44(0)7552637388;

21 tea.basic@cefas.co.uk

${ }^{4}$ Salmon and Freshwater Team, Centre for Environment, Fisheries and Aquaculture Science (Cefas), Pakefield Road, Lowestoft, Suffolk NR33 OHT, UK 


\section{ABSTRACT}

23 The spawning success of lithophilic salmonids is strongly influenced by the fine sediment

24 content ('fines') of spawning substrates, yet knowledge on the impacts of fines on the spawning

25 of non-salmonid lithophiles remains limited, despite their ecological and socio-economic importance in European rivers. Consequently, the aim here was to use an ex-situ experiment to investigate the impact of sand content on egg survival and timing of larval emergence of the surface-spawning cyprinid European barbel Barbus barbus. Thirty incubator boxes within a recirculating system were filled with one of five experimental sediment mixtures (0 to $40 \%$ sand by mass) that each contained 300 fertilised eggs at a depth of $50 \mathrm{~mm}$. Emerged, freeswimming larvae were captured and counted daily to assess grain size effects on larval survival and emergence. Specifically, total proportion of emerged larvae, cumulative daily proportion of emerged larvae and time required to reach $50 \%$ emergence were measured during the study.

34 Whilst the proportion of sand in the sediments did not have a significant impact on egg-toemergence survival (mean survival per treatment $75 \%$ to $79 \%$ ), it significantly affected the timing of larval emergence to the water column; early emergence was detected in treatments

37 with elevated sand content (on average, $50 \%$ emergence after 12 - 13 days versus 19 days in the control). Similar to findings from salmonid studies, these results suggest high sand content

39 in spawning gravels can influence timing of larval emergence and potentially cyprinid $40 \quad$ lithophilic fish survival. 
Availability and suitability of spawning habitats are important determinants of fish population viability in freshwater ecosystems (Bond \& Lake, 2003; Goldstein, D'Alessandro, Reed, \& Sponaugle, 2016; Kondolf, 2000; Parsons, Middleton, Smith, \& Cole, 2014). This is true for lithophilic fish species, whose reproductive success is strongly related to environmental conditions experienced in the substrate during the period of egg incubation and larval development (Balon, 1975; Louhi, Mäki-Petäys, \& Erkinaro, 2008; Mann, 1996; Noble, Cowx,

Goffaux, \& Kestemont, 2007). Local hydraulic conditions, sediment composition and oxygen content are all factors which influence egg and larval development and survival in salmonids (Bloomer, Sear, Dutey-Magni, \& Kemp, 2016; Casas-Mulet, Alfredsen, Brabrand, \& Saltveit, 2015; Sear et al., 2016). Specifically, fine sediment content ('fines', $\leq 2 \mathrm{~mm}$ ) and composition (e.g. organic matter content) influence bed porosity and permeability, and oxygen demand in the substratum (e.g. Kemp, Sear, Collins, Naden, \& Jones, 2011; Sear et al., 2014, 2016; Wharton, Mohajeri, \& Righetti, 2017). As such, fines are important in determining reproductive success in lithophilic fishes and there is a strong connection between fine sediment loadings in rivers and anthropogenic activities, primarily land use changes, such as deforestation and agricultural practices (Kemp et al., 2011; Wharton et al., 2017; Wood \& Armitage, 1997).

The direct and indirect impacts of fines on egg and larval survival rates, larval development and emergence have been widely documented for salmonid fishes (e.g. Franssen et al., 2012; Levasseur, Bergeron, Lapointe, \& Bérubé, 2006; Sear et al., 2014, 2016). Direct influences occur pre-hatching when asphyxiation results from river bed sedimentation (Franssen et al., 2012) and the subsequent alterations of flow and oxygen supply to incubating eggs (Greig, Sear, \& Carling, 2005a; Pattison, Sear, Collins, Jones, \& Naden, 2014; Sear et al., 2014; 
Soulsby, Malcolm, \& Youngson, 2001). Fines which infiltrate chorion micropores can inhibit oxygen permeation and metabolic waste removal across the egg membrane (Greig, Sear, Smallman, \& Carling, 2005b; Kemp et al., 2011; Sear et al., 2014). In contrast, post-hatching survival and larval emergence time is strongly dependent on both asphyxiation and entombment mechanisms, which can lead to increased larval mortality (Franssen et al., 2012; Fudge, Wautier, Evans, \& Palace, 2008; Sternecker \& Geist 2010). Indirect impacts of elevated fines in substrates can result from premature or delayed emergence which are driven by reductions in space and oxygen concentration and subsequent changes in metabolic and growth rates (Bloomer et al. 2016; Chapman et al., 2014; Franssen et al., 2012; Sear et al., 2016).

Early emergence can offer some benefits to individuals, given the opportunity to claim high quality territories and switch to exogenous feeding (Einum \& Fleming, 2000; Harwood, Griffiths, Metcalfe, \& Armstrong, 2003; O'Connor, Metcalfe, \& Taylor, 2000). Conversely, early emergers often have small body sizes and a large yolk sac which may increase their susceptibility to predation and downstream displacement (Bloomer et al., 2016; Brännäs, 1995; Franssen et al., 2012; Louhi, Ovaska, Mäki-Petäys, Erkinaro, \& Muotka, 2011). Similarly, impaired development due to sustained exposure to sub-optimal environmental conditions in the substratum can increase susceptibility of late emergers to predation (Bloomer et al., 2016; Brännäs, 1995; Einum \& Fleming, 2000; Louhi et al., 2011; Roussel 2007) and intraspecific competition (Cutts, Metcalfe, \& Taylor, 1999; Einum \& Fleming, 2000).

Most of the work on fines accrual and implications for egg development and larval survival and emergence has focused on salmonid fishes. However, it is important to develop understanding of fines impacts on non-salmonid egg incubation for three reasons. First, within

90 Europe, there are around 75 fish species belonging to the lithophilic group (Noble et al., 2007), 
with $85 \%$ of them being non-salmonid and of considerable socio-economic, recreational and ecological importance (FAME Consortium, 2004). Second, spawning mechanisms of salmonid and non-salmonid lithophiles are similar, thus there is potential for knowledge transfer between the groups. Finally, there are only few studies evaluating the impact of fines on non-salmonid fishes (Leuciscus leuciscus: Mills, 1981; Kemp et al., 2011; Petromyzon marinus: Smith \& Marsden, 2009; and Lampetra fluviatilis: Silva, Gooderham, Forty, Morland, \& Lucas, 2015), emphasising the need for work in this area.

Consequently, the aim of this study was to experimentally test the influence of sand content on egg survival and timing of emergence of an ecologically, recreationally and commercially important non-salmonid lithophilic fish. The lithophile European barbel Barbus barbus was selected due to utilisation of spawning habitats that are similar to salmonids (e.g. depth, water flow, substrate characteristics; Table 1). Thus, egg deposition depth, spawning season and incubation period are comparable to other non-salmonid lithophiles (e.g. Acipenser, Barbus, Leuciscus, Chondrostoma lithophilic species; FAME Consortium, 2004; Kottelat \& Freyhof, 2007), so results may at some level, be transferable between species. B. barbus is also ubiquitous throughout Europe, particularly in the middle and lower reaches of lowland rivers where sedimentation risks are high (Collins \& Walling, 2007; Naura et al., 2016). Sand-sized particles were chosen due to their detrimental influence on egg incubation and larval emergence

110 of salmonids (Bryce, Lomnicky, \& Kaufmann, 2010; Fudge et al., 2008; Lapointe, Bergeron,

111 Bérubé, Pouliot, \& Johnston, 2004; Sear et al., 2016), with the assumption it may influence spawning success of other, un-studied lithophiles. Also, in British lowland rivers where

113 indigenous B. barbus populations are present, such as the River Great Ouse in Eastern England,

114 juvenile recruitment tends to be poor where sand content of spawning gravels exceeds $20 \%$ 115 (Bašić, 2016), highlighting a possible link between sand content and reproductive success. The 
116 hypothesis tested was that variable subsurface sand content will influence egg-to-emergence

117 survival rates and timing of larval emergence of $B$. barbus. In this study, 'larval emergence'

118 refers to both emergence from the subsurface sediment layer to the water column and 119 emergence to the surface sediment layer, with specific references made to each of these 120 throughout the manuscript.

121

122

\section{MATERIALS AND METHODS}

\section{$123 \quad 2.1$ Experimental setup}

124 The experiment tested differences in the number and timing of emerged larvae from a range of 125 sediment mixtures containing different concentrations ( 0 to $40 \%$ ) of sand (0.064 to $2.000 \mathrm{~mm}$ ).

126 Sediments utilised in this experiment were collected from 6 spawning sites of $B$. barbus in the

127 River Great Ouse using a McNeil sampler (core volume $\approx 0.005 \mathrm{~m}^{3}$; McNeil \& Ahnell, 1964) 128 and Koski plunger. Subsurface sediment samples $(n=10$ per site) were dried and sieved into 129 half phi size fractions (0.064 to $45 \mathrm{~mm})$ using an electronic sieve shaker and sieve stacks. The 130 mass of sediment within each discrete size fraction was determined and used to produce grain131 size distributions for each site (see Bašić, Britton, Rice, \& Pledger, 2017 for detailed methodology). River-averaged values were calculated from these data and used to inform

133 selection of sand $(0.064-2 \mathrm{~mm})$ and gravel $(2-45 \mathrm{~mm})$ components that were combined to

134 form experimental sediment mixtures. In each case, gravel and sand components were 135 combined to obtain experimental sediment mixtures with 0 (control), 10, 20, 30 and $40 \%$ (4 136 treatments) sand (Table 2). Particles $<0.064 \mathrm{~mm}$ (silt) were excluded from each of the 137 experimental mixtures as silt impacts on incubation were not the focus of this study. 
139 In Spring 2015, 30 'incubator' boxes (14 L; external dimensions: 0.5 x 0.3 x $0.095 \mathrm{~m}$ ) were

140 installed within a recirculating system consisting of two 500-litre water tanks (one header tank,

141 one sump) and five 200-litre troughs, connected via a series of pipes (Figure 1; Figure S1).

142 These boxes were filled with the different sediment mixtures to an approximate depth of 150

$143 \mathrm{~mm}$ and the total mass of sediment within each box was $14 \mathrm{~kg}$. Incubator boxes were distributed

144 among the 5 troughs so that each trough contained 6 boxes (replicates; Figure 1; Figure S1).

145 Sediment mixtures were disinfected with Virkon S (Antec International Ltd., Sudbury, UK),

146 rinsed, dried and mixed on site, prior to insertion into the incubator boxes.

148 Water flowed through the system from the header tank via gravity, through the UV filter and

149 into the return pipe where water either entered the sump directly or via the troughs, incubator boxes and drain. Before recirculation, sump water was heated using an Elecro 2kW S/S electric heater $(230 \mathrm{v} 1 \mathrm{ph})$ and pumped back to the header tank via the delivery pipe (Figure 1$)$. Water entered each trough through an inflow pipe before being pumped by a small submersible pump,

153 through a manifold and into the incubator boxes. A gate valve on each of the manifold branches

154 allowed for the regulation of flows within incubator boxes. Flow rates within each incubation box were approximately $7 \mathrm{~L} \mathrm{~min}^{-1}$, as per Fudge et al. (2008), and consistent with those measured in the field at $B$. barbus spawning sites (Bašić et al., 2017). The excess water that overflowed the boxes was collected in the troughs and transported away via outflow pipes

158 (Figure 1). To ensure emerged larvae did not escape from each box with the overflowing water,

159 fine mesh $(1 \mathrm{~mm})$ was placed around the outer edges of each box. We observed no fine sediment loss from either the inflow pipes of overflows during the experiment.

162 Following initial set-up, the system was allowed to run for 7 days before adding fertilized $B$.

163 barbus eggs. Flow velocity was measured three times in each box before sediment was added, 
164 just above the inflow outlet using a side-facing Nortek Vectrino, sampling at $100 \mathrm{~Hz}$ for 60

165

166

167

168

169

170

171

172

173

174

175

176

177

178

180

181

182

183

184

185

186

187 seconds. This was to ensure flow conditions were consistent between the different treatments and control. Importantly, no significant differences in the vertical component of velocity were detected (one-way ANOVA; $F_{(4,25)}=1.07, P>0.05$ ). Additionally, water velocity within each of the incubator boxes was measured after the addition of sediment. Measurements were made just above the sediment surface $(10-20 \mathrm{~mm})$ at three locations per incubator box, using the equipment and procedure described above. Mean values of the vertical component of velocity from each trough were used as a proxy for interstitial water velocity at the start of the experiment. Mean velocity was $0.01 \pm 0.002 \mathrm{~ms}^{-1}$, well above the minimal interstitial flow velocity associated with high salmon embryo survival $\left(4.17 \mathrm{e}^{-05} \mathrm{~ms}^{-1}\right.$; Franssen et al., 2012; Greig, Sear, \& Carling, 2007). Therefore, it was assumed that initial conditions within incubation boxes were suitable for egg incubation.

\subsection{Collection and seeding of Barbus barbus eggs}

Fertilized B. barbus eggs were provided by the Environment Agency of England, a government-funded organisation responsible for fisheries management and regulation. Eggs and milt were extracted from one female (fork length: $690 \mathrm{~mm}$; mass: $4.5 \mathrm{~kg}$ ) and 2 males (fork lengths: 490 and $530 \mathrm{~mm}$ ) under anaesthetic, following two rounds of hormone injections (carp pituitary extract; $0.1 \mathrm{ml} / \mathrm{kg}$ ) over a 24-hour period. A single female was used to ensure consistent levels of fertilisation between experimental replicates. Following fertilization in the hatchery (Figure S1), eggs were immediately transferred to the experimental recirculating system located on site (Figure 1; Figure S1). Approximately 300 eggs were deposited inside each spawning box (Table 3) at a depth of $100 \mathrm{~mm}$ and covered with a $50 \mathrm{~mm}$ layer of additional sediment. The exact number of eggs per box was determined using image analysis 
in Image J (Schneider, Rasband, \& Eliceiri, 2012; Figure S1) of photographs of the eggs prior to their deposition in the incubator boxes. Eggs were not counted manually due to time constraints and high sensitivity of $B$. barbus eggs to handling (personal observation by Bašić).

192 All eggs were deposited 24/05/15 at 06:00, marking the start of the experiment. Water 193 temperature was initially set at $16{ }^{\circ} \mathrm{C}$ but increased to $17.5^{\circ} \mathrm{C}$ five days later when hatching started to ensure optimal conditions for egg and larvae development (Wijmans, 2007). The experiment utilized a 14:10 h light: dark photoperiod (Policar, Podhorec, Stejskal, Hamackova, \& Hadi Alavi, 2010, 2011), controlled by timer-operated lamps above each of the incubator

197 boxes. Water temperature, $\mathrm{pH}$, conductivity, dissolved oxygen and unionized ammonia 198 concentration were monitored at least two times per day per replicate using a YSI probe, ensuring physico-chemical water conditions were suitable ( $c f$ Policar et al., 2010, 2011; Wijmans, 2007), relatively constant and importantly, consistent between replicates of the different treatments and control (temperature: $17.54 \pm 0.11{ }^{\circ} \mathrm{C}$; dissolved oxygen concentration: $8.25 \pm 0.05 \mathrm{mgl}^{-1} ; \mathrm{pH}: 8.04 \pm 0.01$; conductivity: $738.38 \pm 3.27 \mu \mathrm{Scm}^{-1}$; unionized nitrogen ammonia concentration: $0.03 \pm 0.001 \mathrm{mgl}^{-1}$ ). Our monitoring tested for differences in environmental conditions as a function of the experimental design and found none, with measured parameters consistent between each of the troughs and so, treatments and the control (Linear mixed effects models; temperature: $\chi^{2}(4)=0.06, P>0.05$; dissolved oxygen

207 concentration: $\chi_{(4)}^{2}=2.83, P>0.05 ; \mathrm{pH}: \chi_{(4)}^{2}=0.31, P>0.05$; conductivity: $\chi_{(4)}^{2}=0.85, P>$ 208 0.05; unionized nitrogen ammonia concentration: $\left.\chi_{(4)}^{2}=7.7, P>0.05\right)$. It is therefore reasonable to assume any differences in environment (specifically, flows and water chemistry) and so, emergence, are a result of the different treatment/control sediment mixtures, rather than

211 experimental design. Furthermore, environmental conditions were consistent with those 
212 described in literature and mimicked natural conditions in UK lowland rivers around the time

213 of spawning.

215 Each egg box was inspected twice daily (morning and evening) for emerged larvae. Direct egg

216 hatching success could not be assessed as B. barbus larvae are photophobic after hatching and

217 remained in the sediment until yolk sac absorption (Balon, 1975; Vilizzi \& Copp, 2013). Thus,

218 pre-emergence survival was assessed as the proportion of eggs that resulted in an emerged

219 larva. The timing of emergence was assessed when larvae emerged from the substrate into the

220 surface water column, allowing their capture with an aquarium net without disturbing the

221 sediments. We observed no attempts by free-swimming larvae to re-enter the sediment during

222 collection although some did stay close to the bed, presumably to avoid detection and so, capture. A variety of capture techniques were considered, including use of pipettes, but these methods were rejected due to time constraints and high sensitivity of $B$. barbus larvae to handling (personal observation by Bašić). Emergence to the surface water column began on day 12 of the experiment and typically coincided with yolk sac exhaustion (personal observation by Bašić). However, emergent larvae with the yolk sac intact were observed on the sediment surface of treatments with high sand content (30 and $40 \%$ ) from day 5 of the experiment. These larvae could not be removed without sediment disruption, so were left and recovered following emergence to the water column. Consequently, body length and size of

231 the yolk sac immediately after emergence from the gravels could not be assessed during the 232 experiment.

234 Upon emergence to the water surface, larvae were captured daily from treatment and control 235 incubation boxes, counted and transferred to separate holding cages $(0.17 \times 0.13 \times 0.13 \mathrm{~m})$. 236 Daily enumeration and removal of emergent larvae continued through the emergence period 
and after 3 consecutive days of no emergence from any treatment/control, the experiment concluded. Upon experiment completion fish were stocked into a nursery pond but no subsequent measurements of physiology or fate were made.

\subsection{Data analysis}

242 The effect of substrate composition on egg to emergence survival was assessed using a generalized linear mixed model (GLMM) with the proportion of eggs that resulted in an emerged larva in each replicate (as a value between 0 and 1) and treatment specified as a response variable and fixed effect, respectively (Table 4). In addition, each sample was fitted as a random effect on the intercept to correct for over-dispersion and validated accordingly post fit (Bolker et al., 2009; Harrison, 2014). The impact of treatment on time (in days) required to reach $50 \%$ emergence was quantified using a linear model (LM) (Table 4).

The difference in emergence timing across treatment was assessed using a GLMM where the cumulative proportion of daily emerged larvae to the water column (each daily proportion value per replicate was added to previous available proportions to establish total proportion of emerged larvae for a certain day and treatment) was specified as a response variable and the interaction of treatment and time a fixed effect. Each incubator box was specified as a nested random effect on the intercept to account for temporal dependency of data (Table 5).

GLMMs were fitted by maximum likelihood using a Laplace approximation (family-binomial; link-logit; Zuur, Ieno, Walker, Saveliev, \& Smith, 2009) in R (R Development Core Team, 2011) package lme4 (Bates, Maechler, Bolker, \& Walker, 2015). Model assumptions were checked using standard graphical validation for GLMM and LM in R (Zurr et al., 2009). The significance of fixed effect/s for each model was assessed using an $F$ test (LM) or Wald test 
262 (GLMMs) in the R car package (Fox \& Weisberg 2011). Following a significant effect of treatment on egg to emergence survival, time to $50 \%$ emergence or proportion of emerged

264 larvae, comparisons of covariate adjusted means were conducted via least-squares means with

265 Dunnett adjustments for $P$ values for multiple independent comparisons using multcomp 266 package in R (Hothorn, Bretz, \& Westfall, 2008).

\section{RESULTS}

Over the 21-day experimental period, the proportion of eggs that survived to larval emergence was similar across treatments (Wald $\chi_{(4)}^{2}=1.37 ; P=0.85$; Table 5; Figure 2) and average egg survival to larval emergence never exceeded $80 \%$ (Table 3; Figure 2).

Time required to reach $50 \%$ emergence was significantly affected by Treatment $\left(F_{(4,25)}=\right.$ 45.19; $P<0.01$; Table 4; Figure 3) with significant differences detected when comparing control vs. treatment data (Table 4; Figure 3). On average, more than $50 \%$ of larvae emerged from the 40 and $30 \%$ sand treatments on day 12 and 13 of the experiment, respectively. However, for 10 and $20 \%$ treatments and the control, $50 \%$ emergence was reached on average on day 16, 17 and 19 of the experiment, respectively (Figure 3 and 4).

280 The interaction of treatment and experimental time had a significant effect (Wald $\chi^{2}{ }_{(49)}=$ $281113921 ; P<0.01)$ on the proportion of emerged larvae to the surface water column between treatments (Table 5). Dunnett's pairwise comparison revealed significant differences between proportions of larvae emerged to the surface water in the control and $10 \%$ sand treatment from

284 the thirteenth day of the experiment $(\mathrm{z}=2.55, P=0.04$; Table 5) until the nineteenth day of 285 the experiment $(\mathrm{z}=1.33, P=0.47$; Table 5$)$. The daily proportions of emerged larvae to the surface water varied significantly between the control and $20 \%$ sand treatment from day 12 (z 
$287=4.58, P=0.01$; Table 5$)$ to day 18 of the experiment $(\mathrm{z}=2.42, P=0.05$; Table 4$)$, but the overall rate of emergence equalized thereafter (Table 5; Figure 4).

289

290 Treatments with the highest amounts of sand (30 and $40 \%$ ) differed significantly in the rate of

291 daily emergence from the control, with a general pattern of more rapid emergence rates to the surface water column (Table 4). Most of these larvae emerged from the sediment 5 days after the start of the experiment in 30 and $40 \%$ sand treatments, but their capture and enumeration were not possible prior to their emergence to the water column. Consequently, proportion of emerged larvae to the surface water column between treatments with 30 and $40 \%$ sand and control differed significantly from day $12(\mathrm{z}=8.02, P<0.01$ and $\mathrm{z}=9.46, \quad P<0.01$, respectively) until day 19 of the experiment $(\mathrm{z}=2.117, P=0.10$ and $\mathrm{z}=1.62, P=0.30$, respectively) (Table 5; Figure 4).

\section{DISCUSSION}

301 Sand content did not significantly impact upon $B$. barbus egg to emergence survival rates in this experiment. However, timing of larval emergence differed between treatments with high sand content (30 and $40 \%$ ) and control conditions. Most larvae from the high sand treatments moved to the sediment surface on day 5 and appeared to have their yolk sacs intact and were unable to swim, but enumeration was not possible until emergence to the surface water column.

306 Correspondingly, larvae from treatments with 30 and $40 \%$ sand emerged to the water surface earlier than control larvae, which took 8 additional days to reach $50 \%$ larval emergence.

309 There are three plausible reasons for the early emergence detected during this experiment. First,

310 smaller gaps between grains in the 30 and $40 \%$ sand treatments may have limited the body 311 size at which larvae could emerge (Sear et al. 2016), meaning larvae left the substrate earlier 
312 to avoid entombment. Second, it is reasonable to assume larvae exposed to the 30 and $40 \%$

313 sand treatments were at increased risk of abrasion due to increased availability of fines. Thus,

314 fish exposed to these sediment mixtures may have emerged prematurely to avoid risk of

315 damage, which may have influenced survival. Third, low oxygen levels within sediments with

316 high fines may have caused premature emergence as shown in several studies (e.g. Bloomer et

317 al., 2014; Chapman et al., 2014; Sear et al., 2016). Regardless of the driver of early emergence,

318 our observations suggest the timing of emergence had a significant impact on larval physiology

319 immediately post-emergence, with larvae emerging early from substrates with 30 and $40 \%$

320 sand appearing smaller and with a larger yolk sack. These observations are broadly supported

321 by quantitative data from other studies. Franssen et al. (2012) showed premature emergence of

322 Salvelinus fontinalis in fines-rich sediment $(<0.5 \mathrm{~mm})$ under controlled conditions. The body

323 size and weight of larvae was smaller in earlier emerged individuals and the yolk sack was

324 larger. Similarly, prematurely emerged larvae of wild Salvelinus confluentus had a larger yolk

325 sac at a site with high fine sand content $(<1 \mathrm{~mm}:>18 \%)$ in subsurface sediments (Bowerman,

326 Neilson, \& Budy, 2014). This is comparable to our treatments with $30 \%$ and $40 \%$ sand $(<1$

327 mm component: $21.4-28.5 \%$ ), where earlier emergence of larvae was observed (Day 5 of the

328 experiment). However, this did not correspond with higher mortality rates, as the numbers of

329 emerged larvae equalized after 16 days (Day 21 of the experiment) across all treatments.

331 Other investigations into emergence of salmonid species found limited impacts of fine

332 sediment on larval survival. For example, no significant differences in survival and total 333 emergence were detected for Salmo salar and Oncorhynchus mykiss larvae between treatments

334 with variable fine sediment content (Fudge et al., 2008; MacCrimmon \& Gots, 1985).

335 However, emergence patterns changed with sediment treatment such that in MacCrimmon and

336 Gots (1985), mean time to initial emergence to the water column and time to median emergence 
were shorter in sand-rich substrates $(<4 \mathrm{~mm})$. Specifically, $90.9 \%$ of larvae migrated towards

338 the surface immediately after hatching in treatments with $60-100 \%$ fines, with delayed

339 emergence observed for treatments with 20 and $0 \%$ fines (MacCrimmon \& Gots, 1985). In

340 addition, and in line with our observations, early emergers were significantly smaller and had

341 a larger yolk sac in comparison to larvae from low fines treatments (MacCrimmon \& Gots,

342 1985). Fudge et al. (2008) also observed changes in temporal patterns of emergence from sand-

343 rich substrates $(<4 \mathrm{~mm})$. He identified greater emergence in sand-rich substrates $(>25 \%)$

344 initially as a result of unsuitable conditions in the hyporheic layer, with emergence rates

345 declining with sand seal formation. However, larvae condition and yolk sac did not

346 significantly differ between treatments (Fudge et al., 2008). Longer residence times in the

347 substratum could be advantageous in the wild because it can provide sufficient nourishment

348 and protection from predation and downstream drift until a size is reached at which that

349 individual has higher competence to avoid sub-optimal conditions (Bowerman et al., 2014;

350 Chapman et al., 2014; Sear et al., 2016). However, this can be offset by longer exposure to

351 unsuitable conditions, resulting in impaired development and survival post-emergence

352 (Brännäs, 1995; Einum \& Fleming, 2000; Roussel, 2007). Furthermore, longer residence in the

353 substratum increases the risk of predation by egg-eating predators (Chotkowski \& Marsden,

354 1999; Edmonds, Riley, \& Maxwell, 2011; Johnson \& Ringler, 1979) and entrainment by high

355 flows (Lisle 1989; Montgomery, Beamer, Pess, \& Quinn, 1999; Montgomery, Buffington,

356 Peterson, Schuett-Hames, \& Quinn, 1996), with the latter two particularly relevant for shallow

357 spawners such as B. barbus.

358

359 Given lack of information on the factors influencing reproductive success in B. barbus. it is

360 important to compare risks associated with the life history and spawning strategies of the

361 species vs. those of other, better-studied lithophiles. Sand content had no recognisable 
influence on the survival of $B$. barbus eggs or larvae during the experiment. For salmonid species, there is typically an inverse relationship between sand content and recruitment

364 (Lapointe et al., 2004; Sear et al., 2016; Zimmerman \& Lapointe, 2005), with mortalities expected for UK salmonids (e.g. Salmo salar, Salmo trutta) where $<1 \mathrm{~mm}$ and $<2 \mathrm{~mm}$ particles make up over 5.4 - 15 and 10 - $20 \%$ of the bed, respectively (Table 1). Pacific Salmon are also

367 less tolerant of substrates with fines exceeding $7.5-21(<1 \mathrm{~mm})$ and $11 \%(<2 \mathrm{~mm})($ Table 1). Longer incubation time of salmonid eggs and larvae (four to six months) in the gravel (Hendry, Hensleigh, \& Reisenbichler, 1998; Malcolm, Middlemas, Soulsby, Middlemas, \& Youngson, 2010; Murray \& McPhail, 1988) can increase risk of entombment (Franssen et al., 2012; Fudge et al., 2008; Sternecker \& Geist, 2010) and likelihood of asphyxiation resulting from elevated sedimentation rates during early development (e.g. Bowerman et al., 2014; Levasseur et al., 2006; Sear et al., 2016). In contrast, B. barbus spawns during late spring in warmer conditions, thus their incubation time is significantly shorter, often less than two weeks, depending on temperature (Wijmans, 2007; Kemp et al., 2011). Salmonid eggs and larvae are typically buried at comparatively greater depths in the substratum (mean bottom egg pocket depth: $28.6 \mathrm{~cm}$; Table 1) as opposed to shallow spawners such as B. barbus (around 5 cm; personal observation by Bašić), which may impose a higher risk of entombment (Lisle, 1989, Montgomery et al., 1996; Wijmans, 2007). However, risks of predation and egg entrainment are presumably higher for shallow-spawning fishes. A shorter incubation time appears to have been advantageous for B. barbus in this study, although spring/summer spawning and shallow burial depth could also increase egg and larval predation risk, given elevated metabolic rates and so, food requirements of piscivorous predators around that time. As incubation time and egg burial depth could have significant implications for reproductive success of different fish species, greater understanding of the nature of spawning and its impact 
on species resistance to environmental stressors is therefore required to aid conservation efforts.

Comparing experimental conditions to the River Great Ouse, where the mean sand composition of spawning substrates is $>20 \%$ (Bašić, 2016), implies that sand concentrations could be causing early larval emergence in the river. Premature emergence may have implications for post-emergent larval survival. Indeed, several other studies have reported influences of premature emergence on larval survival due to their smaller bodies and larger yolk sacs, which prevents them from avoiding predators and maintaining position without being displaced (Bowerman et al., 2014; Chapman et al., 2014; Franssen et al., 2012; Sear et al., 2016). This could at least partially explain the low natural recruitment of B. barbus in the area despite adults being observed spawning on some gravels on an annual basis (Twine, 2013). Moreover, the river suffers high abundances of invasive signal crayfish (Bašić, 2016) that could predate on both $B$. barbus eggs due to their shallow spawning nature and prematurely emerged larvae on the surface (Copp, Godard, Vilizzi, Ellis, \& Riley, 2017; Edmonds, Riley, \& Maxwell, 2011).

401

Increased sedimentation can reduce the natural resilience of freshwater ecosystems to present and future perturbations, with growing populations and so, demands for food and agriculture, likely to exacerbate ecological impacts. Furthermore, climate change scenarios project increased air temperatures and alterations of precipitation patterns (UKCP09: Murphy et al., 2009), potentially reducing river flows and increasing sedimentation rates. Anthropogenic activities and their impacts on river hydrology and geomorphology can have major implications for lithophilic species, potentially influencing fish recruitment and viability. With scarce knowledge on early development of non-salmonid lithophilic fishes, there is a requirement to 410 investigate impacts of fine sediment on egg survival and larval emergence of a range of species 
under in- and ex-situ conditions. Coupled with knowledge of spawning habitat conditions in

412 rivers for a variety of species, these data can inform threshold setting based on the quality of

413 fluvial sediment and the biological impact. Such data could be used to inform managers on the

414 efficiency of different sediment mitigation options in relation to predefined biological targets,

415 as a first step in seeking to appropriately manage fish spawning habitats (Bašić et al., 2017).

416

417 In summary, the experiment revealed that high sand content in the spawning gravels influenced emergence timing of $B$. barbus, but not egg or larval survival. The pattern of early emergence is hypothesised to be important in contributing to observed low recruitment success of $B$. barbus in the river Great Ouse and other similar systems.

\section{ACKNOWLEDGEMENTS}

We thank Alan Henshaw and his team at Calverton Fish Farm for their support, provision of eggs and space for completing the experiment. We also thank three anonymous reviewers for their positive and constructive comments. TB was supported by a $\mathrm{PhD}$ studentship from Bournemouth University, the Environment Agency and the Barbel Society.

\section{REFERENCES}

Armstrong, J.D., Kemp, P.S., Kennedy, G.J.A., Ladle, M., \& Milner, N.J. (2003). Habitat requirements of Atlantic salmon and brown trout in rivers and streams. Fisheries research, 62, 143-170. https://doi.org/10.1016/S0165-7836(02)00160-1 
Bašić, T. (2016). Applied ecology and management of a European barbel Barbus barbus population of a lowland river (PhD thesis). Bournemouth, UK: Faculty of Science and Technology, Bournemouth University.

Bašić, T., Britton, J.R., Rice, S.P., \& Pledger, A.G. (2017). Impacts of gravel jetting on the composition of fish spawning substrates: Implications for river restoration and fisheries management.

Ecological

Engineering,

107,

71-81. https://doi.org/10.1016/j.ecoleng.2017.06.057

Bates, D.M., Maechler, M., Bolker, B., \& Walker, S. (2015). Fitting Linear Mixed-Effects Models Using lme Journal of of Statistical Software, 67, $1-48$. https://doi.org/10.18637/jss.v067.i01

Bloomer, J., Sear, D., Dutey-Magni, P., \& Kemp, P. (2016). The effects of oxygen depletion due to upwelling groundwater on the posthatch fitness of Atlantic salmon (Salmo salar). Canadian Journal of Fisheries and Aquatic Sciences,

73, $1830-1840$. https://doi.org/10.1139/cjfas-2016-0189

Bolker, B.M., Brooks, M.E., Clark, C.J., Geange, S.W., Poulsen, J.R., Stevens, M.H.H., \& White, J.-S.S. (2009). Generalized linear mixed models: a practical guide for ecology and evolution. Trends in Ecology and Evolution,

24. 127-135. https://doi.org/10.1016/j.tree.2008.10.008

Bond, N. R., \& Lake, P. S. (2003). Characterizing fish-habitat associations in streams as the first step in ecological restoration. Austral Ecology, 28, 611-621. https://doi.org/10.1046/j.1442-9993.2003.t01-1-01317.x

Bowerman, T., Neilson, B.T., \& Budy, P. (2014). Effects of fine sediment, hyporheic flow, and 456 spawning site characteristics on survival and development of bull trout embryos. Canadian 458 Journal of Fisheries and Aquatic Sciences, 71, 1059-1071. https://doi.org/10.1139/cjfas2013-0372 
Brännäs, E., (1995). First access to territorial space and exposure to strong predation pressure: 460 a conflict in early emerging Atlantic salmon (Salmo salar L.) fry. Evolutionary Ecology, 9, 411-420. https://doi.org/10.1007/BF01237763

Bryce, S.A., Lomnicky, G.A., \& Kaufmann, P.R. (2010). Protecting sediment-sensitive aquatic species in mountain streams through the application of biologically based streambed sediment criteria. Journal of the North American Benthological Society, 29, 657-672. https://doi.org/10.1899/09-061.1

Casas-Mulet, R., Alfredsen, K., Brabrand, Å., \& Saltveit, S.J. (2015). Survival of eggs of Atlantic salmon (Salmo salar) in a drawdown zone of a regulated river influenced by groundwater. Hydrobiologia, 743, 269-284. https://doi.org/10.1007/s10750-014-2043-x

Chapman, J.M., Proulx, C.L., Veilleux, M.A., Levert, C., Bliss, S., Andre, M.E., Lapointe, 470 N.W., \& Cooke, S.J. (2014). Clear as mud: a meta-analysis on the effects of sedimentation

Chotkowski, M.A., \& Marsden, J.E. (1999). Round goby and mottled sculpin predation on lake trout eggs and fry: field predictions from laboratory experiments. Journal of Great Lakes Research, 25, 26-35. https://doi.org/10.1016/S0380-1330(99)70714-8

Collins, A.L., \& Walling, D.E. (2007). Sources of fine sediment recovered from the channel bed of lowland groundwater-fed catchments in the UK. Geomorphology, 88, 120-138. https://doi.org/10.1016/j.geomorph.2006.10.018

Copp, G.H., Godard, M.J., Vilizzi, L., Ellis, A., \& Riley, W.D. (2017). Predation by invasive 480 signal crayfish on early life stages of European barbel may be limited. Aquatic Conservation: Marine and Freshwater Ecosystems, 0, 1-5. https://doi.org/10.1002/aqc.2768 
483 Curry, R.A., Noakes, D.L., \& Morgan, G.E. (1995). Groundwater and the incubation and 484 emergence of brook trout (Salvelinus fontinalis). Canadian Journal of Fisheries and Aquatic 485 Sciences, 52, 1741-1749. https://doi.org/10.1139/f95-766

486 Cutts, C.J., Metcalfe, N.B., \& Taylor, A.C. (1999). Competitive asymmetries in territorial 487 juvenile Atlantic salmon, Salmo salar. Oikos, 86, 479-486. https://doi.org/10.2307/3546652 488 DeVries, P. (1997). Riverine salmonid egg burial depths: review of published data and 489 implications for scour studies. Canadian Journal of Fisheries and Aquatic Sciences, 54, 490 1685-1698. https://doi.org/10.1139/f97-090

491 Edmonds, N.J., Riley, W.D., \& Maxwell, D.L. (2011). Predation by Pacifastacus leniusculus 492 on the intra-gravel embryos and emerging fry of Salmo salar. Fisheries Management and Ecology, 18, 521-524. https://doi.org/10.1111/j.1365-2400.2011.00797.x

494 Einum, S., \& Fleming, I.A. (2000). Selection against late emergence and small offspring in 495

FAME CONSORTIUM (2004). Manual for the application of the European Fish Index - EFI. A fish-based method to assess the ecological status of European rivers in support of the Water Framework Directive. Version 1.1, January 2005.

500 Fox, J., \& Weisberg, S. (2011). An $\{$ R $\}$ Companion to Applied Regression, Second Edition. Thousand Oaks CA: Sage. URL: http://socserv.socsci.mcmaster.ca/jfox/Books/Companion.

502 Franssen, J., Blais, C., Lapointe, M., Bérubé, F., Bergeron, N., \& Magnan, P. (2012). 503 Asphyxiation and entombment mechanisms in fines rich spawning substrates: experimental 504 and Aquatic Sciences, 69, 587-599. https://doi.org/10.1139/f2011-168

506 Fudge, T.S., Wautier, K.G., Evans, R.E., \& Palace, V.P. (2008). Effect of different levels of 507 fine-sediment loading on the escapement success of rainbow trout fry from artificial redds. 

https://doi.org/10.1577/M07-084.1

510 Goldstein, E.D., D'Alessandro, E.K., Reed, J., \& Sponaugle, S. (2016). Habitat availability and 511 depth-driven population demographics regulate reproductive output of a coral reef fish. $512 \quad$ Ecosphere, 7, e01542. https://doi.org/10.1002/ecs2.1542

513 Greig, S.M., Sear, D.A., \& Carling, P.A. (2005a). The impact of fine sediment accumulation on the survival of incubating salmon progeny: implications for sediment management. Science of The Total Environment, 344, 241-258. https://doi.org/10.1016/j.scitotenv.2005.02.010

517 Greig, S.M., Sear, D.A., \& Carling, P.A. (2007). A review of factors influencing the availability 518 of dissolved oxygen to incubating salmonid embryos. Hydrological Processes, 21, 323-334. https://doi.org/10.1002/hyp.6188

Greig, S.M., Sear, D.A., Smallman, D., \& Carling, P.A. (2005b). Impact of clay particles on the cutaneous exchange of oxygen across the chorion of Atlantic salmon eggs. Journal of Fish Biology, 66, 1681-1691. https://doi.org/10.1111/j.0022-1112.2005.00715.x

Hanrahan, T.P., Dauble, D.D., \& Geist, D.R. (2004). An estimate of Chinook salmon (Oncorhynchus tshawytscha) spawning habitat and redd capacity upstream of a migration barrier in the upper Columbia River. Canadian Journal of Fisheries and Aquatic Sciences, 61, 23-33. https://doi.org/10.1139/f03-140

Harrison, X.A. (2014). Using observation-level random effects to model overdispersion in count data in ecology and evolution. PeerJ, 2, p.e616. https://doi.org/10.7717/peerj.616

Harwood, A.J., Griffiths, S.W., Metcalfe, N.B., \& Armstrong, J.D. (2003). The relative influence of prior residency and dominance on the early feeding behaviour of juvenile Atlantic salmon. 
533 Hendry, A.P., Hensleigh, J.E., \& Reisenbichler, R.R. (1998). Incubation temperature, 534 developmental biology, and the divergence of sockeye salmon (Oncorhynchus nerka) within

535 Lake Washington. Canadian Journal of Fisheries and Aquatic Sciences, 55, 1387-1394. 536 https://doi.org/10.1139/f98-020

537 Hothorn, T., Bretz, F., \& Westfall, P. (2008). Simultaneous Inference in General Parametric $538 \quad$ Models. Biometrical Journal, 50, 346-363. https://doi.org/10.1002/bimj.200810425

539 Johnson, J.H., \& Ringler, N.H. (1979). Predation on Pacific salmon eggs by salmonids in a 540 tributary of Lake Ontario. Journal of Great Lakes Research, 5, 177-181. $541 \quad$ https://doi.org/10.1016/S0380-1330(79)72144-7

542 Kemp, P., Sear, D., Collins, A., Naden, P., \& Jones, I. (2011). The impacts of fine sediment on 543 riverine fish. Hydrological Processes, 25, 1800-1821. https://doi.org/10.1002/hyp.7940

544 Kondolf, G.M. (2000). Assessing salmonid spawning gravel quality. Transactions of the 545 American Fisheries Society, 129, 262-281. https://doi.org/10.1577/1548$546 \quad 8659(2000) 129<0262:$ ASSGQ $>2.0 . C O ; 2$

547 Kondolf, G.M., \& Wolman, M.G. (1993). The sizes of salmonid spawning gravels. Water $548 \quad$ Resources Research, 29, 2275-2285. https://doi.org/10.1029/93WR00402

549 Kottelat, M., \& J. Freyhof, (2007). Handbook of European freshwater fishes. Berlin: $550 \quad$ Publications Kottelat.

551 Lapointe, M.F., Bergeron, N.E., Bérubé, F., Pouliot, M.A., \& Johnston, P. (2004). Interactive 552 effects of substrate sand and silt contents, redd-scale hydraulic gradients, and interstitial 553 velocities on egg-to-emergence survival of Atlantic salmon (Salmo salar). Canadian Journal of Fisheries and Aquatic Sciences, 61, 2271-2277. https://doi.org/10.1139/f04-236 fine sand dynamics in Atlantic salmon (Salmo salar) redds on embryo hatching 

https://doi.org/10.1139/f06-050

Lisle, T.E. (1989). Sediment Transport and Resulting Deposition in Spawning Gravels, North https://doi.org/10.1029/WR025i006p01303

Lorenz, J.M., \& Filer, J.H. (1989). Spawning habitat and redd characteristics of sockeye salmon in the glacial Taku River, British Columbia and Alaska. Transactions of the American

Louhi, P., Mäki-Petäys, A., \& Erkinaro, J. (2008). Spawning habitat of Atlantic salmon and brown trout: general criteria and intragravel factors. River Research and Applications, 24, 330-339. https://doi.org/10.1002/rra.1072

Louhi, P., Ovaska, M., Mäki-Petäys, A., Erkinaro, J., \& Muotka, T. (2011). Does fine sediment constrain salmonid alevin development and survival? Canadian Journal of Fisheries and Aquatic Sciences, 68, 1819-1826. https://doi.org/10.1139/f2011-106

MacCrimmon, H.R., \& Gots, B.L. (1986). Laboratory observations on emergent patterns of juvenile Atlantic salmon, Salmo salar, relative to sediment loadings of test substrate. Canadian journal of zoology, 64, 1331-1336. https://doi.org/10.1139/z86-198

Magee, J.P., McMahon, T.E., \& Thurow, R.F. (1996). Spatial variation in spawning habitat of cutthroat trout in a sediment-rich stream basin. Transactions of the American Fisheries Society, 125, 768-779.

Malcolm, I.A., Middlemas, C.A., Soulsby, C., Middlemas, S. J., \& Youngson, A. F. (2010). Hyporheic zone processes in a canalised agricultural stream: implications for salmonid https://doi.org/10.1127/1863-9135/2010/0176-0319 
582 Mann, R.H.K., (1996). Environmental requirements of European non-salmonid fish in rivers. 583 Hydrobiologia, 323, 223-235. https://doi.org/10.1007/BF00007848

584 McNeil, W.J., \& Ahnell, W.H. (1964). Success of pink salmon spawning relative to size of 585 spawning bed materials (Report no. 157). Washington: US Department of Interior, Fish and $586 \quad$ Wildlife Service.

587 Mills, C.A., (1981). Egg population dynamics of naturally spawning dace, Leuciscus leuciscus 588 (L.). Environmental Biology of Fishes, 6, 151-158. https://doi.org/10.1007/BF00002778

Moir, H.J., Soulsby, C., \& Youngson, A.F. (2002). Hydraulic and sedimentary controls on the 590 availability and use of Atlantic salmon (Salmo salar) spawning habitat in the River Dee system, north-east Scotland. Geomorphology, 45, 291-308. https://doi.org/10.1016/S0169$555 X(01) 00160-X$

Montgomery, D.R., Beamer, E.M., Pess, G.R., \& Quinn, T.P. (1999). Channel type and 594 salmonid spawning distribution and abundance. Canadian Journal of Fisheries and Aquatic Sciences, 56, 377-387. https://doi.org/10.1139/f98-181

Montgomery, D.R., Buffington, J.M., Peterson, N.P., Schuett-Hames, D., \& Quinn, T.P. (1996). Stream-bed scour, egg burial depths, and the influence of salmonid spawning on bed surface mobility and embryo survival. Canadian Journal of Fisheries and Aquatic Sciences, 53, 1061-1070. https://doi.org/10.1139/f96-028

600 Murphy, J.M., Sexton, D.M.H., Jenkins, G.J., Boorman, P.M., Booth, B.B.B., Brown, C.C., ... 601 Betts, R.A., (2009). UK climate projections science report: UKCP09. Exeter, UK: Met 602 Office Hadley Centre: Exeter, UK.

603 Murray, C.B., \& McPhail, J.D. (1988). Effect of incubation temperature on the development 604 of five species of Pacific salmon (Oncorhynchus) embryos and alevins. Canadian Journal 605 of Zoology, 66, 266-273. https://doi.org/10.1139/z88-038 
606 Naura, M., Hornby, D.D., Collins, A.L., Sear, D.A., Hill, C., Jones, J.I., \& Naden, P.S. (2016).

607 Mapping the combined risk of agricultural fine sediment input and accumulation for riverine

608 ecosystems across England and Wales. Ecological Indicators, 70, 209-221. 609 https://doi.org/10.1016/j.ecolind.2016.03.055

610 Noble, R.A.A., Cowx, I.G., Goffaux, D., \& Kestemont, P. (2007). Assessing the health of 611 European rivers using functional ecological guilds of fish communities: standardising 612 species classification and approaches to metric selection. Fisheries Management and 613 Ecology, 14, 381-392. https://doi.org/10.1111/j.1365-2400.2007.00575.x

614 O'Connor, W.C.K., \& Andrew, T.E. (1998). The effects of siltation on Atlantic salmon, Salmo 615 salar L., embryos in the River Bush. Fisheries Management and Ecology, 5, 393-401. 616 https://doi.org/10.1046/j.1365-2400.1998.550393.x

617 O'Connor, K.I., Metcalfe, N.B., \& Taylor, A.C. (2000). The effects of prior residence on 618 behavior and growth rates in juvenile Atlantic salmon (Salmo salar). Behavioural Ecology, 619 11, 13-18. https://doi.org/10.1093/beheco/11.1.13

620 Parsons, D.M., Middleton, C., Smith, M.D., \& Cole, R.G. (2014). The influence of habitat 621 availability on juvenile fish abundance in a northeastern New Zealand estuary. New Zealand 622 Journal of Marine and Freshwater Research, 48, 216-228. https://doi.org/10.1080/00288330.2013.875927

624 Pattison, I., Sear, D. A., Collins, A. L., Jones, J. I., \& Naden, P. S. (2014). Interactions between 625 fine-grained sediment delivery, river bed deposition and salmonid spawning. IN: Jun Xu, 626 Y. et al. (eds.) Sediment Dynamics From the Summit to the Sea. Wallingford: IAHS, 199627 206. https://doi.org/10.5194/piahs-367-199-2015

628 Policar, T., Podhorec, P., Stejskal, V., Hamackova, J., \& Hadi Alavi, S. M. (2010). Fertilization 629 and hatching rates and larval performance in captive common barbel (Barbus barbus L.) 

https://doi.org/10.1111/j.1439-0426.2010.01564.x

632 Policar, T., Podhorec, P., Stejskal, V., Kozák, P., Švinger, V., \& Hadi Alavi, S. M. (2011).

633 Growth and survival rates, puberty and fecundity in captive common barbel (Barbus barbus

634 L.) under controlled conditions. Czech Journal of Animal Science, 56, 433-442.

635 R Development Core Team (2011). R: A language and environment for statistical computing.

636 Vienna, Austria: R Foundation for Statistical Computing. Retrieved from http://www.R637 project.org/.

638 Roussel, J.M. (2007). Carry-over effects in brown trout (Salmo trutta): hypoxia on embryos 639 impairs predator avoidance by alevins in experimental channels. Canadian Journal of $640 \quad$ Fisheries and Aquatic Sciences, 64, 786-792. https://doi.org/10.1139/f07-055

641 Schneider, C.A., Rasband, W.S., \& Eliceiri, K.W. (2012). NIH Image to ImageJ: 25 years of 642 image analysis. Nature methods, 9, 671-675. https://doi.org/10.1038/nmeth.2089. Retrieved 643 from https://imagej.nih.gov/ij/

644 Sear, D.A., Jones, J.I., Collins, A.L., Hulin, A., Burke, N., Bateman, S., Pattison, I., \& Naden, 645 P.S. (2016). Does fine sediment source as well as quantity affect salmonid embryo mortality 646 and development? Science of The Total Environment, 541, 957-968. 647 https://doi.org/10.1016/j.scitotenv.2015.09.155

648 Sear, D.A., Pattison, I., Collins, A.L., Newson, M.D., Jones, J.I., Naden, P.S., \& Carling, P.A. 649 (2014). Factors controlling the temporal variability in dissolved oxygen regime of salmon 650 spawning gravels. Hydrological Processes, 28, 86-103. https://doi.org/10.1002/hyp.9565

651 Silva, S., Gooderham, A., Forty, M., Morland, B., \& Lucas, M.C. (2015). Egg drift and 652 hatching success in European river lamprey Lampetra fluviatilis: is egg deposition in gravel 653 vital to spawning success? Aquatic Conservation: Marine and Freshwater Ecosystems, 25, 654 534-543. https://doi.org/10.1002/aqc.2486 
655 Smith, S.J., \& Marsden, J.E. (2009). Factors affecting sea lamprey egg survival. North 656 American Journal of Fisheries Management, 29, 859-868. https://doi.org/10.1577/M07$657 \quad 196.1$

658 Soulsby, C., Malcolm, I.A., \& Youngson, A.F. (2001). Hydrochemistry of the hyporheic zone 659 in salmon spawning gravels: a preliminary assessment in a degraded agricultural stream. 660 River Research and Applications, 17, 651-665. https://doi.org/10.1002/rrr.625

661 Sternecker, K., \& Geist, J. (2010). The effects of stream substratum composition on the 662 emergence of salmonid fry. Ecology of Freshwater Fish. 19, 537-544. 663 https://doi.org/10.1111/j.1600-0633.2010.00432.x

664 Twine, K.G. (2013). Conservation of barbel (B. barbus) in the River Great Ouse (PhD thesis). 665 Hull, UK: Faculty of Science and Engineering, University of Hull.

666 Vilizzi, L., \& Copp, G.H. (2013). Interstitial movement and emergence of barbel Barbus 667 barbus free embryos and larvae. Journal of fish biology, 82, 1057-1063. 668 https://doi.org/10.1111/jfb.12033

669 Wentworth, C.K. (1922). A scale of grade and class terms for clastic sediments. The journal of 670 geology, 30, .377-392.

671 Wharton, G., Mohajeri, S.H., \& Righetti, M. (2017). The pernicious problem of streambed 672 colmation: a multi-disciplinary reflection on the mechanisms, causes, impacts, and 673 management challenges. Wiley Interdisciplinary Reviews: Water, 4, e1231. 674 https://doi.org/10.1002/wat2.1231

675 Wijmans, P.A.D.M. (2007). Kennisdocument barbeel, Barbus barbus (Linnaeus, 1758) [report 676 on barbel ecology, Barbus barbus] (Report 14). Bilthoven, Netherlands: Sportvisserij $677 \quad$ Nederland.

678 Wood, P.J., \& Armitage, P.D. (1997). Biological effects of fine sediment in the lotic 679 environment. Environmental management, 21, 203-217. 
680 Zimmermann, A.E., \& Lapointe, M. (2005). Intergranular flow velocity through salmonid 681 redds: sensitivity to fines infiltration from low intensity sediment transport events. River 682 Research and Applications, 21, 865-881. https://doi.org/10.1002/rra.856

683 Zuur, A.F., Ieno, E.N., Walker, N.J., Saveliev, A.A., \& Smith, G.M. (2009). Mixed effects 684 models and extensions in ecology with R. New York, NY: Spring Science and Business $685 \quad$ Media.

686

\section{AUTHORS' CONTRIBUTION STATEMENT}

688 All four authors have been involved throughout the project and contributed significantly to the

689 writing. Specifically:

690 Conceived and designed the investigation: TB, AP, RB;

691 Performed field and/or laboratory work: TB, AP;

692 Analysed the data: TB, AP, RB;

693 Contributed materials, reagents, and/or analysis tools: TB, AP, RB, SR;

694 Wrote the paper: TB, AP, RB, SR.

695

696

697

698

699

700

701

702

703 
715 Table 1. Summary of spawning habitat preferenes of salmonids (Armstrong, Kemp,

716 Kennedy, Ladle, \& Milner, 2003 ${ }^{\text {a }}$; Bowerman et al., 2014 ${ }^{\text {b }}$ Bryce et al., 2010 ; Curry \&

717 Noakes, 1995 ${ }^{\mathrm{d}}$; DeVries, 1997e ; Franssen et al., 2012 ${ }^{\mathrm{f}}$; Hanrahan, Dauble, \& Geist, 2004

718 Kondolf, 2000 ; Kondolf \& Wolman, 1993 ${ }^{\mathrm{i}}$; Lorenz \& Filer, 1989 ${ }^{\mathrm{j}}$; Louhi et al., 2008 ${ }^{\mathrm{k}}$;

719 Magee, McMahon, \& Thurow, 1996' Moir, Soulsby, \& Youngson, 2002 ${ }^{\mathrm{m}}$; O'Connor \& 720 Andrew, $\left.1998^{\mathrm{n}}\right)$.

\begin{tabular}{|c|c|c|c|c|c|c|c|c|c|}
\hline \multirow[t]{2}{*}{ Species } & \multicolumn{2}{|c|}{$\begin{array}{l}\text { Egg burial } \\
\text { depth }(\mathrm{cm})\end{array}$} & \multirow{2}{*}{$\begin{array}{l}\text { Water } \\
\text { depth } \\
\text { (cm) }\end{array}$} & \multirow{2}{*}{$\begin{array}{l}\text { Water } \\
\text { flow } \\
(\mathrm{cm} / \mathrm{s})\end{array}$} & \multirow[t]{2}{*}{ D50 (mm) } & \multicolumn{4}{|c|}{ Fines threshold (\%) } \\
\hline & Top & Bottom & & & & $\begin{array}{l}<1 \\
\mathrm{~mm}\end{array}$ & $\begin{array}{l}<2 \\
\mathrm{~mm}\end{array}$ & $\begin{array}{l}<3.5 \\
\mathrm{~mm}\end{array}$ & $\begin{array}{l}<6.35 \\
\mathrm{~mm}\end{array}$ \\
\hline $\begin{array}{l}\text { Salmo } \\
\text { salar }\end{array}$ & $15^{\mathrm{e}}$ & $30^{\mathrm{e}}$ & $\begin{array}{l}20-50^{\mathrm{k}} \\
17-76^{\mathrm{a}}\end{array}$ & $\begin{array}{l}35-65^{\mathrm{k}} \\
35-80^{\mathrm{a}}\end{array}$ & $\begin{array}{l}15-16.6^{\mathrm{i}} \\
20-30^{\mathrm{a}} \\
16-64^{\mathrm{k}}\end{array}$ & $\begin{array}{l}5.4^{\mathrm{a}} \\
10^{\mathrm{k}} \\
15^{\mathrm{n}}\end{array}$ & $10-20^{\mathrm{m}}$ & & \\
\hline $\begin{array}{l}\text { Oncorhynchus } \\
\text { kisutch }\end{array}$ & $15^{\mathrm{e}}$ & $35^{\mathrm{e}}$ & & & $5.4-35^{\mathrm{i}}$ & $7.5-21^{\mathrm{h}}$ & & $30-36^{\mathrm{h}}$ & \\
\hline $\begin{array}{l}\text { Oncorhynchus } \\
\text { keta }\end{array}$ & $15^{\mathrm{e}}$ & $35^{\mathrm{e}}$ & & & $9.6-62^{i}$ & & & $27^{\mathrm{h}}$ & \\
\hline $\begin{array}{l}\text { Oncorhynchus } \\
\text { tshawytscha }\end{array}$ & $15^{\mathrm{e}}$ & $50^{\mathrm{e}}$ & $30-950^{g}$ & $25-225^{g}$ & $10.8-69^{\mathrm{i}}$ & & $11^{\mathrm{c}}$ & & $15-40^{\mathrm{h}}$ \\
\hline $\begin{array}{l}\text { Oncorhynchus } \\
\text { gorbuscha }\end{array}$ & $15^{\mathrm{e}}$ & $35^{\mathrm{e}}$ & & & $6.5-11^{\mathrm{i}}$ & & & & \\
\hline
\end{tabular}




\begin{tabular}{|c|c|c|c|c|c|c|c|c|c|}
\hline $\begin{array}{l}\text { Oncorhynchus } \\
\text { nerka }\end{array}$ & $10^{\mathrm{e}}$ & $25^{\mathrm{e}}$ & & $10-15^{\mathrm{j}}$ & $14.5-48^{\mathrm{i}}$ & & & & $33^{\mathrm{h}}$ \\
\hline $\begin{array}{l}\text { Salmo } \\
\text { trutta }\end{array}$ & $8^{e}$ & $25^{\mathrm{e}}$ & $\begin{array}{l}15-45^{\mathrm{k}} \\
6-82^{\mathrm{a}}\end{array}$ & $\begin{array}{l}20-55^{\mathrm{k}} \\
11-80^{\mathrm{a}}\end{array}$ & $\begin{array}{l}5.8-50^{\mathrm{i}} \\
8-128^{\mathrm{a}} \\
16-64^{\mathrm{k}}\end{array}$ & $8-12^{a}$ & $10^{\mathrm{k}}$ & & \\
\hline $\begin{array}{l}\text { Salvelinus } \\
\text { fontinalis }\end{array}$ & $5^{\mathrm{e}}$ & $15^{\mathrm{e}}$ & $30-70^{d}$ & & $7.2-10.7^{\mathrm{i}}$ & & $10-22^{\mathrm{f}}$ & & \\
\hline $\begin{array}{l}\text { Oncorhynchus } \\
\text { mykiss }\end{array}$ & $10^{\mathrm{e}}$ & $25^{\mathrm{e}}$ & & & $10.5-46.3^{\mathrm{i}}$ & $12^{\mathrm{h}}$ & $16^{\mathrm{c}}$ & $7.7-24^{\mathrm{h}}$ & $30-40^{\mathrm{h}}$ \\
\hline $\begin{array}{l}\text { Salvelinus } \\
\text { confluentus }\end{array}$ & $10^{\mathrm{e}}$ & $20^{\mathrm{e}}$ & & & & & $11^{\mathrm{c}}$ & & $20-30^{\mathrm{b}}$ \\
\hline $\begin{array}{l}\text { Oncorhynchus } \\
\text { clarkii }\end{array}$ & $10^{\mathrm{e}}$ & $20^{\mathrm{e}}$ & $6-27^{1}$ & & $3.2-25.4^{1}$ & $3-17.9^{1}$ & $19^{c}$ & & $\begin{array}{l}20^{\mathrm{h}} \\
12.1-41.6^{\mathrm{l}}\end{array}$ \\
\hline
\end{tabular}

721

722

723

724 Table 2. Grain size distributions of sand gravel mixtures used in control and treatment

725 incubation boxes, expressed in weight percentages. Number of replicates are represented 726 by $n$.

\section{Treatment}

\begin{tabular}{|c|c|c|c|c|c|c|}
\hline \multirow{4}{*}{$\begin{array}{l}\text { Wentworth } \\
\text { (1922) class }\end{array}$} & \multirow{4}{*}{$\begin{array}{l}\text { Grain } \\
\text { size } \\
(\mathrm{mm})\end{array}$} & \multirow{2}{*}{$\begin{array}{l}\text { Control } \\
\text { no sand }\end{array}$} & \multirow{2}{*}{$\begin{array}{l}10 \% \\
\text { sand }\end{array}$} & \multirow{2}{*}{$\begin{array}{l}20 \% \\
\text { sand }\end{array}$} & \multirow{2}{*}{$\begin{array}{l}30 \% \\
\text { sand }\end{array}$} & \multirow{2}{*}{$\begin{array}{l}40 \% \\
\text { sand }\end{array}$} \\
\hline & & & & & & \\
\hline & & & & & & \\
\hline & & $(n=6)$ & $(n=6)$ & $(n=6)$ & $(n=6)$ & $(n=6)$ \\
\hline & & $\%$ & $\%$ & $\%$ & $\%$ & $\%$ \\
\hline \multirow[t]{3}{*}{ Silt } & 0.06 & 0.00 & 0.00 & 0.00 & 0.00 & 0.00 \\
\hline & 0.13 & 0.00 & 0.13 & 0.27 & 0.40 & 0.53 \\
\hline & 0.25 & 0.00 & 0.58 & 1.17 & 1.75 & 2.33 \\
\hline \multirow[t]{3}{*}{ Sand } & 0.50 & 0.00 & 3.21 & 6.41 & 9.62 & 12.83 \\
\hline & 1.00 & 0.00 & 3.19 & 6.39 & 9.58 & 12.77 \\
\hline & 2.00 & 0.00 & 2.88 & 5.77 & 8.65 & 11.54 \\
\hline
\end{tabular}




\begin{tabular}{|c|c|c|c|c|c|c|c|}
\hline & & Total & $0 \%$ & $10 \%$ & $20 \%$ & $30 \%$ & $40 \%$ \\
\hline \multirow{8}{*}{ Gravel } & 2.80 & & 5.17 & 4.65 & 4.13 & 3.62 & 3.10 \\
\hline & 4.00 & & 7.30 & 6.57 & 5.84 & 5.11 & 4.38 \\
\hline & 5.60 & & 7.84 & 7.06 & 6.27 & 5.49 & 4.70 \\
\hline & 8.00 & & 11.32 & 10.18 & 9.05 & 7.92 & 6.79 \\
\hline & 11.20 & & 14.45 & 13.01 & 11.56 & 10.12 & 8.67 \\
\hline & 16.00 & & 18.43 & 16.59 & 14.75 & 12.90 & 11.06 \\
\hline & 22.40 & & 17.48 & 15.73 & 13.98 & 12.23 & 10.49 \\
\hline & 31.50 & & 18.02 & 16.21 & 14.41 & 12.61 & 10.81 \\
\hline & & Total & $100 \%$ & $90 \%$ & $80 \%$ & $70 \%$ & $60 \%$ \\
\hline
\end{tabular}


Table 3. Initial number of $B$. barbus eggs and percentage survival of eggs to surface water emergence per box and treatment.

\begin{tabular}{|c|c|c|c|c|c|c|c|c|c|c|}
\hline \multirow{2}{*}{$\begin{array}{l}\text { Treatment } \\
\text { Box }\end{array}$} & \multicolumn{2}{|l|}{ Control } & \multicolumn{2}{|c|}{$10 \%$ Sand } & \multicolumn{2}{|c|}{$20 \%$ Sand } & \multicolumn{2}{|c|}{$30 \%$ Sand } & \multicolumn{2}{|c|}{$40 \%$ Sand } \\
\hline & $\mathbf{N}($ eggs $)$ & \%Survival & $\mathbf{N}($ eggs $)$ & \%Survival & $\mathrm{N}$ (eggs) & \%Survival & $\mathbf{N}($ eggs) & \%Survival & $\mathbf{N}($ eggs) & \%Survival \\
\hline 1 & 226 & 87 & 452 & 91 & 253 & 79 & 258 & 75 & 174 & 66 \\
\hline 2 & 215 & 99 & 384 & 72 & 245 & 71 & 290 & 65 & 221 & 80 \\
\hline 3 & 292 & 77 & 273 & 100 & 333 & 89 & 243 & 77 & 348 & 67 \\
\hline 4 & 308 & 62 & 324 & 70 & 282 & 77 & 269 & 88 & 144 & 86 \\
\hline 5 & 309 & 78 & 257 & 73 & 349 & 80 & 256 & 79 & 240 & 82 \\
\hline 6 & 330 & 44 & 427 & 69 & 304 & 74 & 210 & 67 & 224 & 83 \\
\hline Mean & 280.0 & 74.5 & 352.8 & 79.2 & 294.3 & 78.3 & 254.3 & 75.2 & 225.2 & 77.3 \\
\hline$( \pm \mathrm{SE})$ & $( \pm 19.5)$ & $( \pm 7.9)$ & $( \pm 33.0)$ & $( \pm 5.3)$ & $( \pm 17.2)$ & $( \pm 2.5)$ & $( \pm 11.0)$ & $( \pm 3.4)$ & $( \pm 28.6)$ & $( \pm 3.5)$ \\
\hline
\end{tabular}

729 
731 Table 4. Results of LM testing for the effect of treatment on the time required to $50 \%$

732 emergence. Mean differences are from estimated least-square means, significant at $* P<$ $733 \quad 0.05$ and $* * P<0.01$.

\section{Model:}

Time to $50 \%$ emergence $\sim$ Treatment $\left(F_{(4,25)}=45.19 ; P<0.01\right)$

\begin{tabular}{lll}
\hline Contrast & $\mathbf{z}$ & Mean difference $( \pm$ SE) \\
\hline Control, day $12-10 \%$ sand, day 12 & 2.96 & $1.67 \pm 0.56, P<0.05^{*}$ \\
Control, day $12-20 \%$ sand, day 12 & 5.32 & $3.00 \pm 0.56, P<0.01^{* *}$ \\
Control, day $12-30 \%$ sand, day 12 & 9.76 & $5.50 \pm 0.56, P<0.01^{* *}$ \\
Control, day $12-40 \%$ sand, day 12 & 11.53 & $6.50 \pm 0.56, P<0.01^{* *}$ \\
\hline
\end{tabular}

734

735

736

737

738

739

740

741

742

743

744 
745 Table 5 Results of GLMMs testing: 1) differences in egg to emergence survival between treatments, 2) differences in cumulative proportion of daily emerged larvae to the surface

747 water between treatments. Mean differences are from estimated least-square means, $748 \quad$ significant at $* P<0.05$ and $* * P<0.01$.

\section{Models:}

1. Egg to emergence survival $\sim$ Treatment $+(1 \mid$ Sample $)$, weights=Total number of eggs (family - binomial (link-logit); Laplace approximation; Wald $\chi_{(4)}^{2}=1.37 ; P=0.85$

2. Cumulative daily emergence $\sim$ Time $x$ Treatment $+(1 \mid$ Trough/Replicate $)$, weight $=$ Total number of eggs, (family - binomial (link-logit); Laplace approximation, Wald $\chi^{2}{ }^{(49)}=$ $113921 ; P<0.01)$

\begin{tabular}{lll}
\hline Contrast & $\mathbf{Z}$ & Mean difference $( \pm$ SE) \\
\hline Control, day $12-10 \%$ sand, day 12 & -1.48 & $-0.46 \pm 0.31, P=0.38$ \\
Control, day $12-20 \%$ sand, day 12 & -4.58 & $-1.40 \pm 0.31, P<0.01^{* *}$ \\
Control, day $12-30 \%$ sand, day 12 & -8.02 & $-2.44 \pm 0.30, P<0.01^{* *}$ \\
Control, day $12-40 \%$ sand, day 12 & -9.46 & $-2.88 \pm 0.30, P<0.01^{* *}$ \\
\hline Control, day $13-10 \%$ sand, day 13 & -2.55 & $-0.77 \pm 0.30, P<0.05^{*}$ \\
Control, day $13-20 \%$ sand, day 13 & -6.93 & $-2.08 \pm 0.30, P<0.01^{* *}$ \\
Control, day $13-30 \%$ sand, day 13 & -10.74 & $-3.24 \pm 0.30, P<0.01^{* *}$ \\
Control, day $13-40 \%$ sand, day 13 & -11.41 & $-3.45 \pm 0.30, P<0.01^{* *}$ \\
\hline Control, day $14-10 \%$ sand, day 14 & -3.65 & $-1.10 \pm 0.30, P<0.01^{* *}$ \\
Control, day $14-20 \%$ sand, day 14 & -7.47 & $-2.25 \pm 0.30, P<0.01^{* *}$ \\
Control, day $14-30 \%$ sand, day 14 & -12.22 & $-3.70 \pm 0.30, P<0.01^{* *}$ \\
Control, day $14-40 \%$ sand, day 14 & -11.72 & $-3.55 \pm 0.30, P<0.01^{* *}$ \\
\hline Control, day $15-10 \%$ sand, day 15 & -2.79 & $-0.82 \pm 0.29, P<0.05^{*}$ \\
Control, day $15-20 \%$ sand, day 15 & -6.20 & $-1.82 \pm 0.29, P<0.01^{* *}$ \\
Control, day $15-30 \%$ sand, day 15 & -9.97 & $-2.95 \pm 0.30, P<0.01^{* *}$ \\
\hline
\end{tabular}




\begin{tabular}{|c|c|c|}
\hline Contrast & $\mathbf{z}$ & Mean difference $( \pm$ SE) \\
\hline Control, day $15-40 \%$ sand, day 15 & -9.36 & $-2.77 \pm 0.30, P<0.01 * *$ \\
\hline Control, day $16-10 \%$ sand, day 16 & -3.01 & $-0.87 \pm 0.29, P<0.01 * *$ \\
\hline Control, day $16-20 \%$ sand, day 16 & -4.28 & $-1.24 \pm 0.29, P<0.01 * *$ \\
\hline Control, day $16-30 \%$ sand, day 16 & -7.31 & $-2.14 \pm 0.29, P<0.01 * *$ \\
\hline Control, day $16-40 \%$ sand, day 16 & -6.67 & $-1.95 \pm 0.29, P<0.01 * *$ \\
\hline Control, day $17-10 \%$ sand, day 17 & -2.72 & $-0.79 \pm 0.29, P<0.05^{*}$ \\
\hline Control, day $17-20 \%$ sand, day 17 & -3.32 & $-0.96 \pm 0.29, P<0.01 * *$ \\
\hline Control, day $17-30 \%$ sand, day 17 & -5.38 & $-1.57 \pm 0.29, P<0.01 * *$ \\
\hline Control, day $17-40 \%$ sand, day 17 & -4.71 & $-1.38 \pm 0.29, P<0.01 * *$ \\
\hline Control, day $18-10 \%$ sand, day 18 & -2.72 & $-0.79 \pm 0.29, P<0.05^{*}$ \\
\hline Control, day $18-20 \%$ sand, day 18 & -2.42 & $-0.70 \pm 0.29, P=0.05$ \\
\hline Control, day $18-30 \%$ sand, day 18 & -4.08 & $-1.19 \pm 0.29, P<0.01 * *$ \\
\hline Control, day $18-40 \%$ sand, day 18 & -3.59 & $-1.05 \pm 0.29, P<0.05^{*}$ \\
\hline Control, day $19-10 \%$ sand, day 19 & -1.33 & $-0.38 \pm 0.29, P=0.47$ \\
\hline Control, day $19-20 \%$ sand, day 19 & -1.01 & $-0.29 \pm 0.29, P=0.68$ \\
\hline Control, day $19-30 \%$ sand, day 19 & -2.12 & $-0.62 \pm 0.29, P=0.11$ \\
\hline Control, day $19-40 \%$ sand, day 19 & -1.62 & $-0.48 \pm 0.29, P=0.30$ \\
\hline Control, day $20-10 \%$ sand, day 20 & -0.70 & $-0.20 \pm 0.29, P=0.85$ \\
\hline Control, day $20-20 \%$ sand, day 20 & -0.47 & $-0.14 \pm 0.29, P=0.94$ \\
\hline Control, day $20-30 \%$ sand, day 20 & -0.81 & $-0.24 \pm 0.29, P=0.79$ \\
\hline Control, day $20-40 \%$ sand, day 20 & 0.32 & $-0.09 \pm 0.29, P 40.98$ \\
\hline Control, day $21-10 \%$ sand, day 21 & -1.26 & $-0.37 \pm 0.29, P>0.05$ \\
\hline Control, day $21-20 \%$ sand, day 21 & -0.79 & $-0.23 \pm 0.29, P>0.05$ \\
\hline Control, day $21-30 \%$ sand, day 21 & -0.57 & $-0.17 \pm 0.29, P>0.05$ \\
\hline Control, day $21-40 \%$ sand, day 21 & -0.11 & $-0.03 \pm 0.29, P>0.05$ \\
\hline
\end{tabular}


751 Figure 1 The set-up of the experimental design, showing the input of water from the

752 borehole, its flow through the UV steriliser and heater and its pumping through the system. The inset image shows detailed view of the experimental set-up inside each

754 trough.

755

756 Figure 2 Average marginal effects and $95 \%$ confidence intervals estimated from the

757 generalized linear mixed-effects model testing the impact of Treatment on egg-to-emergence

758 survival of B. barbus. Letters above bars indicate statistically homogeneous groups.

759

760 Figure 3 Average marginal effects and $95 \%$ confidence intervals estimated from the 761 generalized linear mixed-effects model testing the impact of Treatment on $50 \%$ emergence

762 time of B. barbus. Letters above bars indicate statistically homogeneous groups.

763

764 Figure 4 Line plots showing the marginal effects of variables included in interaction terms

765 (Treatment and Time). $\mathrm{X}$ - axis is the explanatory variable value, representing cumulative 766 daily emergence of $B$. barbus larvae to the surface water column. Dots represent mean values

767 of daily larval emergence ( $\pm 95 \%$ confidence intervals), where (filled circles) control, (filled 768 squares) $10 \%$ sand, (blank triangles) $20 \%$ sand, (blank squares) $30 \%$ sand and (blank circles)

$76940 \%$ sand. Statistically significant differences between control and each of the treatment in 770 time are presented in Table 5. 


\section{Supplementary material}

772 Figure S1 Experimental setup and some of the procedures utilised in the experiment where a)

773 Recirculating system at Calverton fish farm; b) Female B. barbus stripping; and c) An example

774 of the photo used in ImageJ for determining the number of eggs per box and treatment at the

775 start of the experiment. 